relaciones entre comunidades de practicantes en Chiloé.

Palabras clave: Nazareno de Caguach, Religión, Imaginario, Etnografía Histórica, Chiloé-Chile.

\section{Etnografía histórica del Nazareno de Caguach en Chiloé, Chile*}

\author{
Historical ethnography of the Nazareno of \\ Caguach in Chiloé, Chile
}

JuAN M. SaldívaR ${ }^{* *}$

\section{Resumen}

El trabajo muestra hallazgos etnográficos e historiográficos sobre el desarrollo de la tradición religiosa del Nazareno de Caguach en isla Caguach, archipiélago de Chiloé. La discusión contempla el ensamblaje de imaginarios religiosos procedentes del Perú a través de misioneros franciscanos en comunidades isleñas a finales del siglo XIX. Establece una serie de dinámicas culturales que manifiestan estructuras complejas de significado a través de

\begin{abstract}
This work shows ethnographic and historiographical findings on the development of the Nazareno of Caguach religious tradition, in the island of Caguach, in Chiloe. The discussion includes the confluence of religious imaginaries brought from Peru by Franciscan missionaries into the island communities in the late nineteenth century. It establishes cultural dynamics that manifest complex structures of meaning through relations between communities of practitioners in Chiloé.
\end{abstract}

Keywords: Nazareno de Caguach, Religion, Imaginary, Historical Ethnography, Chiloé-Chile.
Este manuscrito forma parte del Proyecto Fondecyt № 3160798 "Etnografías en movimiento, imaginarios culturales y trayectorias migratorias de comunidades transnacionales chilotas entre Ushuaia, Argentina y Punta Arenas, Chile (1950-2015)".

* Doctor en Antropología, Investigador Postdoctorante Programa ATLAS-CEDER, Universidad de Los Lagos. Cochrane \# 1056, Osorno, Chile.E-Mail: juan.saldivar@ulagos.cl 


\section{Introducción}

Llegó el día de la fiesta, llegó el día de la fiesta, entro a la iglesia junto al fiscal, cumplo mi manda frente al altar, cumplo mi manda frente al altar. Tú Nazareno sois poderoso eres pa' todos muy poderoso, eres pa' todos muy poderoso. Oh glorioso Nazareno hoy te canto, te venero, poderoso Nazareno, representas lo primero. Eres tú mi señor para usted lo mejor, eres tu mi piedad voy por ti a Caguach. Los cinco pueblos que hoy te veneran, con viento y lluvia a ti ellos llegan, con viento y lluvia a ti ellos llegan. Llego a la isla treinta de agosto, me voy contento con mi devoto ${ }^{1}$

El estribillo corresponde al canto del Nazareno de Caguach recordado por Víctor Téllez, Fiscal de la capilla Nuestra Señora de Gracia de Nercón en la comuna de Castro. La tradición del Nazareno se manifiesta como una práctica religiosa ensamblada en la Isla Caguach, comuna de Quinchao, archipiélago de Chiloé. Es un culto de religiosidad popular compleja de acuerdo a su procedencia relacionada al Colegio de Propaganda Fide de Santa Rosa de Ocopa en Perú. La representación simbólica en Caguach muestra al Nazareno erguido, llevando la cruz en la espalda, vestido de capa morada, sobre una base de madera en procesión por cuadrillas de cargadores quienes se organizan para el desarrollo de las actividades religiosas. Según Francisco Cavada, el rostro del Nazareno muestra "su expresión angustiosa, lleva al alma un terror santo, un profundo dolor de los pasados yerros" (2016:153). Es acompañado de artefactos (velas, cirios, ropa, monedas) y agrupaciones musicales que entonan melodías alusivas a través del uso del acordeón, guitarra, flauta, violín, caja y bombo. La festividad inicia el 21 de agosto con la novena, el 23 se desarrolla la preva. El resto de los días llegan comunidades de las cinco islas acompañadas del santo patrón,

Víctor Téllez, fiscal, entrevista en profundidad, Castro, Chiloé, julio de 2016. quienes también ayudan en la organización. El día 29 es la ceremonia de las banderas y, el 30 por la mañana, la misa en la Parroquia del Nazareno. Otra fecha conmemorativa se sitúa el tercer domingo de enero, en la que también se desarrollan actividades religiosas vinculadas con el turismo de verano en el archipiélago.

Investigaciones historiográficas sobre el Nazareno atribuyen su origen al grupo de franciscanos que llegaron del "Colegio de Propaganda Fide de Santa Rosa, en Ocopa (con ellos) venía Fray Hilario Martínez, iniciador de la devoción a Jesús Nazareno en la isla Caguach" (Cárdenas \& Trujillo 1986:20). Sin embargo, es latente la posibilidad que relaciona al Nazareno de Caguach con el Señor de los Milagros procedente de Lima. Ambas tradiciones pertenecen a la imaginería judeocristiana promovida por la institución eclesiástica de la Corona española en la Colonia, reservada a los avatares de Jesús de Nazaret. Esto permite pensar en la transformación de la tradición adquirida en los nuevos lugares de asentamiento debido a que algunos códigos estructurales no corresponden a las elaboraciones actuales. Uno de los primeros hallazgos refiere a la consolidación temprana del culto sincrético al Señor de los Milagros en Lima, atribuido a la pintura que hizo un esclavo africano. En este escenario, la llegada de esclavizados provocó anclaje de tradiciones culturales procedentes de África occidental. Esto significó la conexión de imaginarios indígenas, africanos y judeocristianos, siendo "el nexo indispensable, la continuidad entre el pasado mítico y la nueva fe y se tornó en el vehículo necesario para establecer la trayectoria de la transformación y el lazo entre el credo ingenuo y animista con la religión cristiana" (Rostworowski 2002:17). Este hallazgo explica algunos elementos de 
transformación en el Nazareno de Caguach, como son el uso de la indumentaria, la relación con el Cristo Morado (Señor de Los Milagros), conservación de características judeocristianas y aproximación de periodos históricos en la extensión de la tradición en Chiloé.

Los hallazgos etnográficos en este trabajo permitensituartradiciones culturales conservadas en diferentes etapas históricas del archipiélago, así como también en la extensión de la práctica en lugares de la macro zona sur patagónica. Localizar tradiciones religiosas de conformación histórica implica considerar aspectos culturales que permiten imaginar el pasado en el presente. Esto conlleva situar estrategias etnográficas desde una perspectiva histórica, a manera de catalejo, que permite encontrarse con el pasado en diferentes ocasiones circunstanciales. De manera que la etnografía es "una disciplina narrativa (analítica y descriptiva). La etnografía histórica no es una excepción (...) la etnografía en ese sentido es siempre ficción, igual que la historia, es siempre ficción" (Lennartsson 2012: 90). Lo cual sitúa la historia social como "una de las principales manifestaciones de la nueva historiografía comprometida en restituir protagonismos a los sujetos olvidados" (Bolufer 2002:106). El sujeto histórico, es ahora, parte de un nuevo relato alegórico en el que se manifiestan diversos fenómenos que particularizan la realidad social y cultural de uno o más contextos interactuados. La etnografía vista desde la historia se convierte en un flux capacitor que propone entender lo social como ambivalencia, es decir, como sustrato de la doble intención, permitiendo localizar hallazgos culturales desde escenarios narrativos locales.

En este sentido, es relevante precisar el enfoque histórico desde la memoria colectiva como categoría de análisis que permite interpretar el pasado como un proceso dicotómico de imágenes. A finales del sigloXIX, disciplinas como la sociología y la psicología fenomenológica se interesaron por comprender aspectos de la memoria ligados a hechos sociales. Estudiosos como Émile Durkheim (1999) propusieron la idea de conciencia colectiva como forma de ejercer sobre individuos coacción exterior. Su planteamiento ha sido fuertemente cuestionado debido a la presencia de una conciencia que se encuentra sobre o por encima de los individuos. Contrario a esta propuesta, la noción de marcos sociales de la memoria planteada por Maurice Halbwachs, considera aspectos intersubjetivos de análisis siendo los individuos y no los grupos sociales quienes construyen la memoria de acuerdo a experiencias, sucesos o actos en relación con otros. Al mismo tiempo, esta idea de memoria permite recordar el pasado como continuidad de experiencias vividas y no exactamente como la historia escrita o formal propone en la narrativa mediatizada. Estos recuerdos constituidos se reactivan en la escenificación del presente, mediante artefactos u objetos semióticos como museos, monumentos, imágenes y tradiciones religiosas.

Es Jaques Le Goff, quien sugiere pensar la noción de memoria como proceso que, "apunta a salvar el pasado solo para servir al presente y al futuro" (1991:183). Maurice Halbwachs (2004) propone considerar dos aspectos sobre la memoria, por un lado, memoria histórica, como sucesos vividos reconstruidos a través de la individualización y, por otro, memoria colectiva, como recuerdos no conservados del pasado, sino reconstruidos, relatados en el presente. Esto hace pensar la memoria en sentido contrario, es decir, en lo colectivo para interpretar lo histórico y viceversa. El sentido histórico en los 
imaginarios colectivos representa situaciones sobre aquello que Castoriadis (1975), reconoció como mundos instituidos de significados. Son las representaciones como manifestaciones de lo social que constituyen falsos espejismos culturales, sobre todo por entenderse como procesos constituyentes de carácter propio. Es en este engranaje de significados que se enmarcan las tradiciones culturales, cuando estas incorporan particularidades de los contextos geográficos donde se establecen.

\section{Método}

Este artículo siguió lineamientos metodológicos decaráctercualitativo establecidos enel proyecto FONDECYT N. 3160798. Los pasos fueron los siguientes: 1) desarrollar una primera capa de información historiográfica complementada con revisión de documentos y archivos en Biblioteca Pública de Castro, Biblioteca Pública de Chonchi, Archivo Histórico de la Ciudad de Buenos Aires y Archivo Nacional Histórico en Santiago; 2) localización de informantes claves, desarrollo de biografías y entrevistas en profundidad en comunas de Chiloé; 3) análisis fotográfico de ceremonias religiosas en diferentes iglesias del archipiélago. Cabe destacar que este manuscrito se inscribe en un primer cuerpo de conocimiento etnográfico en el que se muestran aspectos historiográficos de la tradición religiosa ensamblada en Caguach y otros lugares de la Isla Grande.

\section{Propaganda e imaginería en Caguach}

Después de la expulsión de los jesuitas (Compañía de Jesús) en Chiloé en 1767, la llegada de franciscanos procedentes del Colegio
Imagen 1. Área de estudio

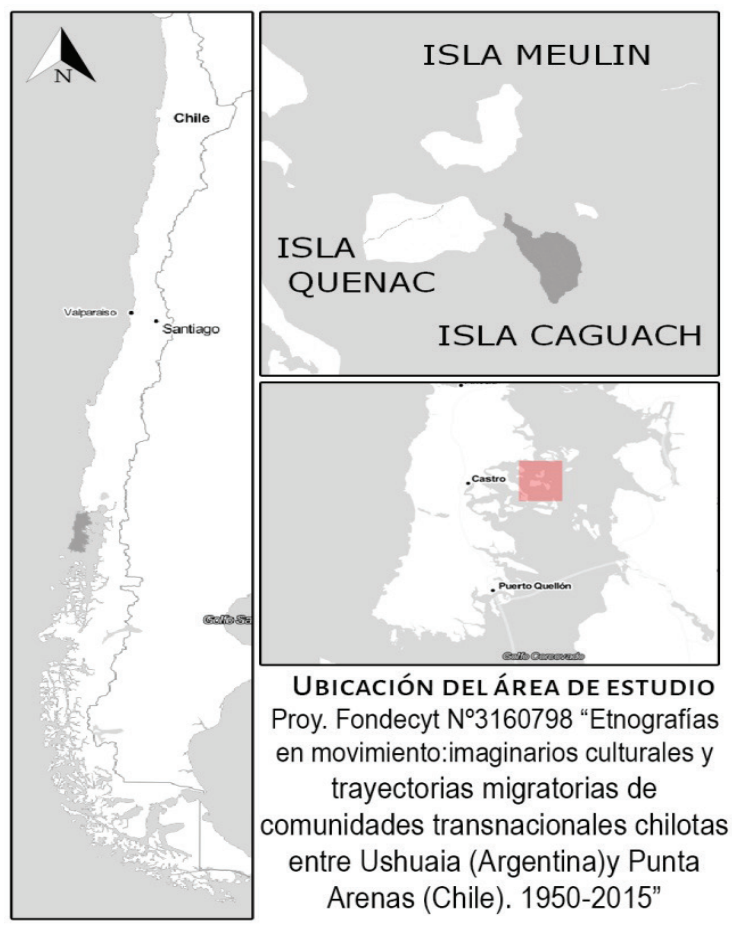

Fuente: Elaboración propia

de Propaganda Fide de Santa Rosa de Ocopa, fue un importante canal que dio continuidad a las actividades religiosas en el archipiélago. Siendo "Pedro Ángel Espiñeira (quien) solicita al "Colegio de Propaganda Fide" de Chillán enviar ministros para cubrir las vacas (sic) que resultaron de la expulsión de los jesuitas (en) 1769 llegaron los ocho misioneros" (Cárdenas \& Trujillo 1986:19-20). Sin embargo, estos regresarían al Colegio San Idelfonso en Chillan siendo un grupo de "quince franciscanos (los que salieron) desde el Callao en viaje a Chiloé (entre estos venía Fray Hilario Martínez quien) reemplazó a Fray Norberto Fernández, primer 
misionero radicado en esa villa en 1771" (Ibíd 1986:20-21). Según narra Víctor Téllez, Fray Hilario era "un curita misionero que salió de la Misión de Santa Rosa de Ocopa de Perú y llegó al sur de Chile, evangelizó a través de imágenes y pintura"2. La estrategia de evangelización franciscana, comenta Renato Cárdenas, fue a partir de "la propaganda Fide, era un programa, había qué hacer con la música, el teatro, el canto y con la misma representación de imágenes"3. Según Alberto Trivero, Fray Hilario "el gallego (antes de llegar a Chiloé) había misionado en Tahití (...) traía consigo una colección de imágenes sagradas" (2011:6).

En su llegada a Tenaún, lugar en el cual se había establecido, "ocurrió un suceso trágico que lo lleva a Caguach en mayo de 1778 llevando sus imágenes después de la carrera entre las cinco islas"4. La carrera fue desarrollada en canoas a remo entre habitantes de los cinco pueblos, Apiao, Alao, Caguach, Chaulinec y Tac, comunidades que adquirieron sus imágenes después de ser repartidas, el Nazareno se quedó en Caguach. Según Alberto Trivero "la colección de Fray Hilario, constituida por ocho imágenes, no fue donada a las cinco comunidades: ellas la compraron, pagando para eso un precio muy elevado, que cancelaron en cuotas anuales desde 1778 hasta 1782" (2011:8). Las narraciones de Renato Cárdenas contradicen lo establecido por Trivero, éste reconoce que "el traslado de las imágenes de Tenaún hasta Caguach no fue fácil, y prácticamente tuvieron que robarlas (...) embarcaron rápidamente las

Víctor Téllez, fiscal, entrevista en profundidad, Castro, Chiloé, julio de 2016

3 Renato Cárdenas, historiador local, entrevista en profundidad, Castro, Chiloé, agosto de 2016.

4 Renato Cárdenas... imágenes y se hicieron a la mar" (1986:22). Una versión pacífica del traslado de imágenes es la que ofrece Víctor Téllez, afirmando que Fray Hilario "llegó a Tenaún con su santo, habló con la gente de Caguach, con el cacique Paulino Guachin en 1778 y así hicieron llegar la imagen"5. Las crónicas ofrecen diferentes versiones sobre el traslado de la imaginería entre las islas, siendo los datos de procedencia foránea en los que mayormente coinciden, atribuyendo origen de Ocopa, Perú, "el caso del Nazareno, encargada en España" (Trivero 2011:10).

Este escenario no solo muestra una serie de evidencias sobre la imaginería religiosa de procedencia peruana en Chiloé, sino también da pistas para entender las intenciones de Fray Hilario en el archipiélago (Arteaga et al 1975), sobre todo porque pretendía construir "un Santuario dedicado a la avocación del Nazareno y de la pasión y muerte de Jesús Crucificado" (Trivero 2011:15). Este hallazgo hace pensar en la influencia de la tradición al Nazareno y, el vínculo asiduo con el Señor de los Milagros limeño, en su representación dramática de crucifixión como éxodo de la pasión de Cristo. Cabe destacar que la imaginería situaba diferentes episodios de la vida religiosa, incluso en la parafernalia como túnicas, escenarios y posiciones de los santos. Fueron revestimientos asociados a momentos históricos (avatares) de entidades y devociones circunstanciales de aquellos que impulsaban las prácticas. Corresponde a la extensión de imaginarios históricos, también icónicos, que desde España se instauraron como parte de las estructuras políticas y simbólicas provocadas por la evangelización (Guarda 1986). Algunos casos de la herencia

Víctor Téllez, fiscal, entrevista en profundidad, Castro, Chiloé, julio de 2016 
multisecular son la Cofradía del Nazareno de la Ciudad de Cádiz, la Primitiva Hermandad de Nazarenos de Sevilla, así también el Señor de los Milagros en Lima y el Nazareno de Caguach, entre otros. De acuerdo a la discusión, Víctor Téllez reconoce que "se le llama según en el lugar que está, con el nombre del lugar al que

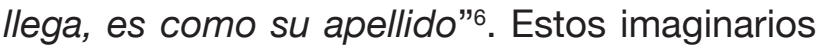
religiosos entrelazados procuran establecer conexiones en la reproducción de significados que permiten seguir custodiando la tradición (de la Torre \& Gutiérrez 2005).

\subsection{Tradición y fiesta del Nazareno}

Los periodos de evangelización en Chiloé se encuentran vinculados a la Compañía de Jesús y Propaganda FIDE de Santa Rosa de Ocopa, ambos pertenecientes a la Corona española establecida en el Perú. Es relevante mencionar cómo las estrategias del Clero religioso precedían de experiencias situadas entre 1581 y 1670, etapa fundante que caracterizó la eliminación de ídolos (extirpación de idolatrías) y aceptación de elementos religiosos. Considerando lo anterior, Manuel Marzal señala, para el caso del Perú, que como parte de la evangelización se calendarizó el año religioso en fiestas patronales o de cargos, forma en la que "Dios se sirvió del engañó para familiarizar a los indios con el catolicismo y facilitar su conversión" (2002:69). En adelante, la etapa de consolidación refiere a la evangelización jerarquizada por significados sincréticos de cristianismo indígena. Este modelo evangelizador fue reproducido en Chiloé, primero por la intervención jesuita, después los franciscanos, quienes formaron personajes jerárquicos como el fiscal o amaricamañ. La creación de estos personajes, donde "amari es pastor y amarintun es una acción que hace la machi para sacar el mal del cuerpo"7, representaban cierta flexibilidad en la incorporación religiosa, provocando estabilidad y liderazgo entre las comunidades. Según Renato Cárdenas, la estrategia basada en el liderazgo indígena correspondía a la selección de personas, "elegían hijos de caciques, de linaje, no viejos sino jóvenes, para irse formando y teniendo mayor presencia entre la comunidad"8.

La figura del fiscal era importante sobre todo por la ausencia de sacerdotes, fungían como guías, tomaban decisiones y encaminaban ciertas actividades como fiestas, ceremonias y reuniones. En este sentido, habría que destacar la configuración de personajes históricos en la vida social chilota que lograban conciliar aspectos religiosos desde el interior de las comunidades. De manera que el cristianismo indígena tomaba cierta posición al solicitarse "la legalidad del fiscal en 1622, logrando legitimarse aproximadamente en 1800 hacia adelante"9. Según Marylin Ulloa, fiscala de la Capilla de Huite, en Quemchi, la función de estos personajes era "mantener la capilla, arreglar flores, el altar, ostias, vino, cantar cantos de entrada, de ofertorio, de comunión"10. Además de las actividades religiosas generales, también se encargaban de "bendecir casas, bautizar niñitos, ponerles el agüita"11. Es relevante destacar el rol que actualmente ostenta el fiscal

\footnotetext{
Renato Cárdenas, historiador local, entrevista en profundidad, Castro, Chiloé, agosto de 2016.

10 Marylin Ulloa, fiscala, entrevista en profundidad, Quemchi, Chiloé, agosto de 2016.
}

8 ídem

9 Ídem

11 Ídem 
como líder espiritual dentro de la comunidad, siendo quien administra la estructura jerárquica en la práctica de tradiciones religiosas. Durante las ceremonias mortuorias, por ejemplo, Marylin Ulloa reconoce que, "son tres o cuatro días que yo tengo que estar, las dos noches de velorio, la misa, hasta el funeral, ellos a mí no me tienen que ir a buscar, yo tengo que ir"12.

Una de las figuras importantes en la práctica religiosa del Nazareno, fue el cabildo, quienes se encargaban de la organización de fiestas a través de cargos. En Caguach, se componía de, "supremo, primer gobernador, primer alcalde, segundo alcalde, primer ministro, segundo ministro, cabo primero, cabo segundo (...) primer alfere (...) primera princesa y segunda princesa" (Cárdenas \& Trujillo 1986:32). Además de cargos menores como "el cadete (...) las acompañadas o vestidoras (...) los comisionados (...) planillero (...) piloto" (lbid 1986:33). Esto significa que cada festividad era organizada por cabildos, siendo la del Santo Patrón o entidad tutelar de la comunidad, la de mayor prestigio. El Nazareno se erigió como la fiesta con mayor arraigo en el archipiélago, arropada por comunidades que se reunían para la partición de actividades. Marylin Ulloa, destaca que en "todas las capillas tenemos el nazareno, pero en Caguach empezó desde antes y tuvo más auge, la misma gente y los curas le dieron más importancia"13. Sin embargo, este tipo de manifestaciones religiosas son cambiantes en el tiempo, sobre todo por considerarse como un sistema de representaciones simbólicas enmarcadas en una estructura cultural (Geertz 1997). Actualmente, la fiesta del Nazareno conserva componentes procedentes de la

\footnotetext{
12 Ídem

13 ídem.
}

Colonia, formas de organización, equiparación de tradiciones católicas e indígenas mapuchehuilliche, estructuras ceremoniales y jerárquicas.

Según Víctor Téllez, la festividad tiene duración de 10 días, iniciando el 21 y culminando el último día de agosto. Es organizada por "los cabildos, siete cargos más la banda, rezadores, músicos, adornadores de la iglesia, vestidores de la imagen, los altares, los arcos, las guirnaldas"14. Incorpora un complejo sistema de símbolos traducidos en elementos de carácter sincrético, "no es llegar y poner, cada arco significa, padre, hijo y espíritu santo, la guirnalda va en cadena, es la unión de la comunidad, las vueltas son en contra de las manecillas del reloj, los nguillatunes hacen lo mismo"15. Las agrupaciones musicales que acompañan las actividades religiosas son elementales en la marcación temporal de ceremonias, consisten en "acordeón, flauta, guitarra, violín, bombo, caja y el pajarito"16. Estas ceremonias son elaboradas a través de evocaciones o rezos, contemplan estructuras con límites establecidos y definidos, "la novena del Nazareno explica la Pasión de Cristo, acto de contrición, ofrecimiento de novena, cinco desagravios, el ejemplo, oración del día, oración de súplica y los gozos"17. También se "cantan las buenas noches, los misterios, las tres coronas, se termina con un canto que se llama échanos tu bendición, todo con la banda"18. La puesta en escena de la festividad es una repetición del pasado mítico, siendo incorporado a través

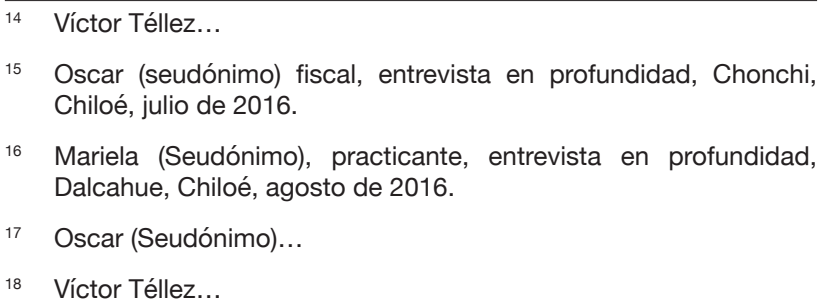

5 Oscar (seudónimo) fiscal, entrevista en profundidad, Chonchi, Chiloé, julio de 2016.

16 Mariela (Seudónimo), practicante, entrevista en profundidad, Dalcahue, Chiloé, agosto de 2016.

17 Oscar (Seudónimo)...

18 Víctor Téllez... 
de la circulación de pasajes ceremoniales que conservan la tradición.

La práctica religiosa del Nazareno consiste en una serie de representaciones performáticas que involucran a personas y escenarios quienes recuerdan y re-activan el pasado mediante la manifestación de paisajes. La puesta en escena de la tradición Nazarena se manifiesta en la vestidura de la imagen, "se le regalan trajes, el día quinto se cambia hasta el día noveno, se viste de nuevo y se perfuma y así se queda hasta el último día, esa ropa se guarda y al final se reparte en trocitos a la comunidad como recuerdo"19. Los participantes se valen de la recreación de escenarios simbólicos en los que interactúan mediante ceremonias religiosas (rituales), como "pagar sus mandas, algunos entran de rodillas, llevan sus velitas, lo primero es tratar de llegar y tocar al santo, luego esperar la misa y la procesión, con sus imágenes y banderas" 20 . Estas dimensiones performativas involucran contextos de exaltación, en palabras de Durkheim (1990), efervescencias colectivas que adquieren significados a través de la integración y regulación de normas. Consideran diversos factores de reproducción, como son propiamente los espacios donde se resaltan aspectos simbólicos del cuerpo en la emergencia de lenguajes en ocasiones no verbales sino afectivos y móviles que, podríamos pensar, llegarían a traspasar la noción del ritual normado, extra-cotidiano, del tiempo profano.

Desde la perspectiva de la teoría de la performance este tipo de manifestaciones rituales podrían entenderse como "dramaturgia del cuerpo", misma que consiste en "una especie de mediación (de) las posibilidades de creación de nexos" (Greiner 2013:202). Es la circulación de actos que provocan interacciones entre espacios y cuerpos, como procesos dicotómicos más amplios de inter-comunicación. Según Isabel de Naverán, "el cuerpo es un archivo de memorias, de técnicas, de modos de hacer (...) su saber se transmite corporalmente, a través de la copia y la repetición, de la memoria y del olvido" (2015:47). La dimensión de los imaginarios se encuentra relacionada con la percepción de signos, los cuales pretenden "explicar e intervenir sobre referencias semejantes de percepción (...) de explicación (marcos lógicos, emocionales, sentimentales, biográficos, etc.)" (Randazzo 2012:79). Según Cornelius Castoriadis (1975), la realidad se constituye e instituye a través de ese magma de significaciones imaginarias, denotando la circulación de patrones y conocimientos sobre estructuras (in)definidas en el espacio y en el tiempo. De otra manera, difícilmente se lograría comprender las comunidades de creencias como acciones de socio-rotación (procesos cíclicos) que condicionan las individualidades en sentido de límites e interferencias de significados simbólicos.

\section{Discusión}

Han sido pocos los estudios desarrollados sobre la tradición religiosa del Nazareno de Caguach en Chiloé, salvo aquellas investigaciones realizadas por Renato Cárdenas y Carlos Trujillo, destacando reflexiones sobre la composición de la religiosidad popular en el archipiélago. En adelante, algunos referentes historiográficos sugieren pensar cómo este tipo de tradiciones religiosas fueron construidas como una plataforma ideológica de intervención 
franciscana que implicaba la equiparación de imaginarios judeocristianos y mapuchehuilliche (Gutiérrez 2007). La formación de estructuras religiosas desde abajo, fueron parte de la estrategia misional de evangelización establecida por la Corona española, sobre todo con intención de convencer a los indígenas locales en una creencia relativizada desde sus propias lógicas culturales (Arteaga Vargas 1975; Cárcamo 1965; Guarda 1968; Mansilla 1991; Urbina 1990). Las misiones circulares en el archipiélago condicionaron la construcción de la memoria histórica religiosa, inspirada en un culto sincrético visibilizado en la territorialización de iglesias $^{21}$ e imaginería judeocristiana ${ }^{22}$ (Guarda 2011; Hanisch 1972; Harter 1934; Moreno Jeria 1999; Montecinos 1995; Muller 2008; Tampe 1981; Urbina 1983). En este sentido, es Jaques Le Goff quien sugiere pensar en la historia como posibilidad de "afrontar los problemas del tiempo (...) en relación con lo cual la memoria se encuentra ya hacia atrás y ya más adelante" (1991:134). Es así que, "la historia no es todo el pasado, pero tampoco es todo lo que queda del pasado (...) junto a la historia escrita hay una historia viva que se perpetúa y renueva a través del tiempo" (Halbwachs 2004:66).

Actualmente la tradición del Nazareno de Caguach es parte de la religiosidad popular de Chiloé, legitimada e institucionalizada en el calendario judeocristiano. La continuidad histórica de las tradiciones implica reflexionar en escenarios recreados, aquellos que han sido construidos precisamente para la conexión

\footnotetext{
Construcción de iglesias cerca del borde costero con acceso al muelle. Ver para mayor detalle, Escuela Chilota de Arquitectura Religiosa en madera (Guarda 1968).

22 Estas misiones se encontraban geográficamente situadas: Misión de Chiloé para los huilliches, de Guar para los chonos, de Cailín para caucahués y taijatafes y de Chonchi para los indios payos del sur.
}

con el pasado, como monumentos, murales, museos y, no menos, tradiciones culturales y religiosas. Es entonces la memoria un flux capacitor que permite no sólo conexión, sino también manifestación de lo vivido a través de imágenes y paisajes interactuados. En este sentido, habría que pensar en el concepto de religión vivida "como un medio para explicar, comprender y moldear la realidad" (Orsi 2006:2). Es precisamente Robert Orsi quien sostiene cómo la religión no debería de entenderse solo como una red de significados, sino también de relaciones que evocan experiencias producto de "las prácticas, los objetos, las presencias (...) los dioses, santos, demonios, ancestros (en) las trayectorias de las personas, en las historias que la gente cuenta sobre ellos" (2006:18). Asimismo, sugiere reflexionar en la noción de religión vivida "como una forma de trabajo cultural (que) atrae la atención hacia las instituciones y las personas, los textos y los rituales, la práctica y la teología, las cosas y las ideas (...) la familia y la sociedad" (2003:172).

Finalmente, se destacan algunas proyecciones futuras en términos de investigaciones sobre el Nazareno de Caguach que, si bien han sido estudiadas en Chiloé, poco se sabe sobre su extensión en lugares de la macro zona sur patagónica. Estudios recientes muestran la transnacionalización de la tradición religiosa en territorios australes de Chile y Argentina (Saldívar 2017). Algunos espacios de reacomodo se encuentran en ciudades de Magallanes como Puerto Natales y Punta Arenas. Del otro lado de la frontera, lugares como Río Gallegos, Río Grande y Ushuaia en Santa Cruz y Tierra del Fuego. Si bien es cierto que este fenómeno religioso se relaciona con diferentes acontecimientos como son particularmente las migraciones de chilotes, también se vincula 
con las actividades económicas, políticas y culturales que los migrantes desarrollan dentro de un campo social transnacional más amplio. De manera que han sido las formaciones de comunidades, extensión de familias rituales y circulación de significados simbólicos que ha provocado construcción de redes religiosas en circuitos alternativos de prácticas multisituadas.

\section{Conclusión}

Después de mostrar algunos hallazgos etnográficos e historiográficos sobre la tradición religiosa del Nazareno de Caguach, es atractivo pensar en un posible vínculo con su equivalente en Lima, referente al Señor de los Milagros. Sobre todo, por aquellos aspectos que comparten como las etapas históricas de formación, estrategias políticas de la Corona española, estructuras simbólicas y actividades relacionadas con lo sagrado. Sin embargo, estas no se encuentran relacionadas de manera directa, debido a la conservación de la memoria histórica local. Jaques Le Goff, menciona que la capacidad de conservar la memoria es a través de la estructuración y auto-organización de sistemas dinámicos de orden, específicos, étnicos y artificiales. La tradición religiosa pertenece a la memoria histórica chilota, no sólo por su ensamblaje y conservación de la práctica, sino también por la incorporación de elementos culturales que la hacen parte del territorio local. Las estructuras simbólicas de lo sagrado (ceremonias del Nazareno) particularizan la tradición y extensión de vínculos colectivos en territorios multisituados, considerando su expansión en lugares de Patagonia, donde ha sido legitimada e institucionalizada en las últimas décadas. Estas subsistencias del pasado histórico, repercuten en el presente a través de la repetición de significados que construyen otras formas de religiosidades, múltiples, asiduas y dinámicas.

La incorporación de la festividad en el calendario religioso, es sin duda, una manifestación de apropiación de códigos culturales que, sin pertenecer históricamente al territorio chilote, se han establecido como esferas imaginarias de lo sagrado. Esta calendarización de la memoria se manifiesta en diferentes aspectos, por ejemplo, la etapa de cristianización en occidente provocó una serie de estructuras litúrgicas en etapas de solemnidad para entidades tutelares, vinculado a un cumulo de performances como plegarias, cantos y otras evocaciones. De manera que fue "una supresión brutal de las tradiciones ligadas al calendario. Toda la vida cotidiana, afectiva, fantástica de una sociedad depende de su calendario" (Le Goff 1991:191). Es entonces la memoria histórica un complejo de significados que "remonta en el pasado hasta un límite determinado, más o menos alejado según se trate de un grupo u otro [....] es precisamente lo que se encuentra más allá de este límite lo que retiene la atención de la historia" (Halbwachs 2004:108).

En este sentido, la tradición del Nazareno se efectúa como parte de una re-memorización que evoca no sólo aspectos religiosos, sino también significados cotidianos en la práctica misma del contexto simbólico en el que se desenvuelven. De manera que "Jesucristo fue crucificado, no sólo en el Gólgota, sino en todos aquellos lugares en que se adore la cruz, y que no sólo comulgó con sus discípulos en el Cenáculo, sino en todos aquellos lugares donde se celebra el sacrificio" (Halbwachs 2004:159). Esto implica considerar también aquellos espacios donde se conmemoran hitos, monumentos y otros sucesos "que atraen a los 
creyentes porque conservamos alguna réplica en ellos, una fuente que cura, una tumba a cuyo alrededor se han producido milagros" (Ibíd:159). Es así que prácticas religiosas se manifiestan como significados dinámicos. Precisamente son estos significados representados en la festividad del Nazareno, los que hacen valer estas condiciones de transformación simbólica, como las campanadas, llamada de la comunidad para la repartición de actividades, siendo el "rosario" el inicio de la novena. La preva o prueba, carrera desarrollada en canoas por los cinco pueblos, recordando el traslado histórico del Nazareno de Tenaún a Caguach. La procesión de las banderas corresponde a una ceremonia de traslación que evoca el resguardo de la imagen a través de la pata danza, organizados en filas de frente que avanzan agitando banderas, haciendo flexión, las banderas simbolizan espadas, el significado es la custodia de los caballeros hacia el Nazareno.

Estas características hacen de la tradición una extensa amalgama de significados que pertenecen al contexto cultural diferenciándose de otras prácticas que las familiarizan. Permiten reflexionar en escenarios del pasado manifestados en el presente, a través de la repetición de paisajes que evocan una serie de relaciones interconectadas con imaginarios multiespaciales. A propósito, Maurice Halbwachs, reconoce que las personas experimentan la memoria histórica "cuando entra [n] en una iglesia, un cementerio o un lugar sagrado, el fiel sabe que ahí va a encontrar un estado de espíritu que ha experimentado ya muchas veces y que va a reconstituir, junto con otros creyentes" (2004:156). Siendo el tiempo histórico el que provoca "una comunidad visible, un pensamiento y unos recuerdos comunes, aquellos que se formaron y mantuvieron en épocas anteriores en el mismo lugar" (Ibíd). Las prácticas religiosas mantienen efervescencias colectivas en medida de las experiencias que se comparten, casi siempre a partir de "que recordemos con detalle y precisión nuestros lazos con el grupo de quienes tienen las mismas creencias que nosotros" (Op.Loc). Son entonces extractos de la memoria histórica las que conducen referencias sobre el pasado, instauradas a través de imágenes, paisajes y escenarios ambivalentes que condicionan la vida religiosa de aquellos que participan e interactúan en comunidad.

\section{Bibliografía}

Arteaga, G. et. al 1975. Estudio para la formulación de un inventario de la imaginería religiosa de Chiloé. Ancud: Universidad Austral de Chile, Seminario Escuela de Educación Básica.

Bolufer, M. 2002. "Entre historia social e historia cultural: la historiografía sobre pobreza y caridad en la época moderna". Historia Social 43: 105-127.

Cárcamo, R. 1965. La institución de los Fiscales en las Provincias de Llanquihue y Chiloé. Santiago: Icla.

Cárdenas, R y Trujillo, C. 1986. Caguach, la isla de la devoción. Religiosidad popular en Chiloé. Santiago, Ediciones LAR.

Castoriadis, C. 1975. La institución imaginaria de la Sociedad. Buenos Aires: Tusquets Editores.
Cavada, F. 2016. [1914] Chiloé y los chilotes. Santiago. Museo Regional de Ancud.

De Naveran, I. 2015. "La danza: aliada perfecta del pasado". AusArt Journal for Research in Art 3 (1): 41-53.

De la Torre, R y Gutiérrez, C. 2005. "La lógica del mercado y la lógica de la creencia en la creación de mercancías simbólicas". Desacatos 18: 53-70.

Durkheim, É. 1990. Les formes élémentaires de la vie religieuse. Le système totémique en Australie. París: PUF. 1999. Les règles de la méthode sociologique. Paris:

Quadrige/Presses Universitaires de France.

Greiner, Ch. 2013. "Investigar la danza en estado salvaje". 
Lecturas sobre danza y coreografía. Naveran, I. y Écija, A. (Editores.) Madrid: Artea Editorial.

Guarda, G. 1968. "El apostolado seglar en la cristianización de América: la institución de los fiscales". Historia7: 205-206. 2011. La edad media de Chile: historia de la iglesia: desde la fundación de Santiago a la incorporación de Chiloé 1541-1826. Santiago: CorpArtes.

Gutiérrez, R. 2007. "Las misiones circulares de los jesuitas en Chiloé. Apuntes para una historia singular de la evangelización". Apuntes 20 (1): 50-69.

Halbawchs, M. 2004. La memoria colectiva. Zaragoza. Prensa Universitaria de Zaragoza.

Hanisch, W. 1972. Itinerario y pensamiento de los jesuitas expulsos de Chile (1767-1815). Santiago de Chile: Editorial Andrés Bello.

Harter, J. 1934. "Los jesuitas en Chiloé y Valdivia (16101767)". Revista San Javier. Suplemento Puerto Montt.

Lennartsson, R. 2012. "Archival Ethnography: reflections on a lost note". Historisches Forum 14: 77-92.

Marzal, M. 2002. Tierra encantada: tratado de antropología religiosa de América Latina. Madrid: Editorial Trotta.

Mansilla, J. 1991. La misión jesuita de los indios chonos en San Felipe de Guar. Puerto Montt: Aurora. Desarrollo Regional del Sur.

Moreno Jeria, R. 1999. Misiones en Chile Austral: los Jesuitas en Chiloé 1608-1768. Sevilla: Universidad de Sevilla.

Montecinos, H. 1995. Las iglesias misionales de Chiloé. Santiago: Universidad de Chile.
Muller, M. 2008. "Jesuitas centro-europeus o «alemanes» en las misiones de indígenas en las antiguas provincias de Chile y del Paraguay". Intus-Legere Historia 1 (2): 205-227.

Orsi, R. 2006. Between heaven and earth. The religious worlds people make and the scholars who study them. Oxford/ Princenton: Princenton University Press.

2003. "Is the study of lived religión irrelevant to the world we live in? Special Presidential Plenary Adrees, Society for the Scientific Study of Religion, Salt Lake City, November 2, 2002". Journal for the Scientific Study of Religion 42 (2): 169-174.

Randazzo, F. 2012. "Los imaginarios sociales como herramienta". Imagonautas 2 (2): 77-96.

Rostworowski, M. 2002. Pachacamac y el Señor de los Milagros: una trayectoria milenaria; señoríos indígenas de Lima y Canta. Lima, Instituto de Estudios Peruanos.

Saldívar, J. 2017. "Chilote tenía que ser". Vida migrante transnacional en territorios patagónicos de Chile y Argentina". CUHSO 27 (2): 175-200.

Tampe, E. 1981. Tres siglos de misiones en Chiloé. Santiago de Chile: Editorial Salesiana.

Trivero, A. 2011. Fray Hilario Martínez. Siguiendo las huellas de su santería. Achao. Inédito.

Urbina, R. 1983. La periferia meridional indiana. Chiloé en el siglo XVIII. Valparaíso: Universidad Católica de Valparaíso. 1990. Las misiones franciscanas de Chiloé a fines de siglo XVIII: 1771-1800. Valparaíso: Universidad Católica de Valparaíso. 